\title{
Self-presentation via electronic word of mouth - a reflective or impulsive activity?
}

\section{Purpose}

Previous research suggests that self-presentation causes people to have a reflective tendency to produce electronic word-of-mouth (eWOM). Drawing on the theory of the reflectiveimpulsive model (RIM), this study examines whether self-presentation also could motivate an impulsive tendency to produce eWOM. Self-monitoring is suggested as a possible moderator in the relationship between self-presentation and impulsive eWOM production.

\section{Design/methodology/approach}

Data was collected based on an online survey of members from a consumer panel. The effective sample size was 574 respondents. Structural equation modeling (SEM) was used to analyze the data.

\section{Findings}

The findings show that self-presentation may drive both impulsive and reflective eWOM tendencies; however, that the relationship between self-presentation and impulsive eWOM tendency is contingent on high levels of self-monitoring.

\section{Originality/value}

By including self-monitoring as a moderator, this study is the first to show a relationship between self-presentation and impulsive eWOM production. Moreover, the findings show that both impulsive and reflective eWOM tendencies are associated with an enhanced tendency to produce eWOM, thereby demonstrating the usefulness of the RIM theory in understanding eWOM behavior. Overall, the findings shed light on how companies may stimulate eWOM production, and consequently provide insight into creating more effective eWOM campaigns.

Keywords: Computer mediated communication; online consumer behavior; viral marketing; word-of-mouth marketing; structural equation modeling 


\section{Introduction}

The enhanced reach and velocity of electronic word-of-mouth (eWOM) compared to traditional word-of-mouth (WOM) has made eWOM a powerful force in the marketplace (Huang et al., 2011). Brand and product related information that consumers share on social networks, review sites and other online channels have the potential to reach millions of other consumers in an instant. At the same time, consumers show an increasing reliance on this kind of information when making their purchase decisions in both B2B (Kim, 2014) and B2C (Schivinski and Dabrowski, 2015) contexts. Consequently, the eWOM phenomenon has become an increasingly important topic for marketing practitioners, and many companies seek to exploit its potential by creating shareable content (Swani et al., 2013) or "social buzz" campaigns (Coker and Altobello, 2016). In order to succeed with such tactics, companies need to understand what motivates consumers to generate and share eWOM (Kozinets et al. 2010).

One motivational factor that seems central to why consumers produce eWOM is selfpresentation (Dunne et al., 2010; Hennig-Thurau et al., 2004). Self-presentation involves managing one's behavior to present a favorable and appropriate image to others (Snyder, 1974). Recent research has highlighted the importance of understanding this human tendency in the context of eWOM, as it may influence both the propensity to produce eWOM (Eisingerich et al., 2015) and what eWOM topics people choose to talk about (Berger and Iyengar, 2013; Lovett et al., 2013).

A key issue in understanding self-presentation as a driver of eWOM is how selfpresentation affects consumers' tendencies to plan and reflect on what to say in their online communication (Walther, 2007). Given the asynchronous nature of most online communication, the common assumption is that people would approach online selfpresentation in a deliberate and reflective manner rather than mindlessly and impulsively. 
This tendency occurs because using more time to plan one's communication increases the chances of achieving one's self-presentation goals. In other words, self-presentation is assumed to motivate the production of eWOM through a reflective thought process rather than based on consumers' impulses and spontaneity (Berger and Iyengar, 2013).

However, a stream of research based in psychology indicates that self-presentation might also happen impulsively and with little reflection (Paulhus, 1993). Such impulsive selfpresentation may occur because people, through repeated practice, learn and automatize behaviors that present themselves in positive terms. The average consumer engages in several WOM conversations each day (Keller and Fay, 2012), and would presumably be well-trained in using WOM as a means for self-presentation. Thus, it is not unlikely that consumers could be able to self-present while giving eWOM produced in a more spontaneous manner. However, little is known about the relationship between self-presentation and impulsive communication in the context of eWOM. First of all, does it exists at all? Second, if the relationship exists, when would it occur?

The current research investigates the above questions based on the assumption that consumers vary in their ability to self-present, and that this ability influences consumers' tendency to self-present through eWOM based on reflection versus impulses. Specifically, for consumers with a high ability to self-present, self-presentation should be a highly automatized activity. Thus, self-presenting through impulsive eWOM may be a relatively easy task. On the other hand, for those with a low self-presentational ability, self-presentation should be less automatized, thus making them more reliant on planning what to say when self-presenting. Self-monitoring is a commonly used trait for measuring people's self-presentational ability (Lennox and Wolfe, 1984). Thus, this study seeks to investigate whether self-monitoring may explain if consumers engage in impulsive eWOM to fulfil self-presentational motives, and 
possibly when consumers would use an impulsive versus reflective mode of communication to fulfil such motives.

In doing so, the study makes important contributions to the current literature. First, to understand the difference between impulsive and reflective eWOM communication, this study adopts the reflective-impulsive model (RIM) as an overarching framework (Strack and Deutch, 2006). This study is the first to use this dual-system theory in the examination of the underlying processes of eWOM production. Importantly, this study's empirical findings show that both impulsive and reflective eWOM communication are associated with an enhanced tendency to give eWOM, thereby extending the RIM theory to a new consumer behavioral domain beyond purchase.

Second, to the best of the author's knowledge, this is the first research to demonstrate that self-presentation may drive both impulsive and reflective eWOM communication. The relationship between self-presentation and impulsive eWOM communication is revealed by the inclusion of self-monitoring as a moderator. Thus, this study shows that studying selfpresentation as a motivational factor is, in isolation, limiting in understanding whether consumers engage in reflective or impulsive eWOM. By adding a trait that measures selfpresentational abilities to the equation, this study shows how self-presentation as a driver of eWOM (Berger and Iyengar, 2013; Walther, 2007) is extendable to also include impulsive eWOM.

For marketing practitioners, this study generates important knowledge with regard to creating eWOM campaigns. First, the results indicate that consumers with a higher tendency to give impulsive eWOM could be a promising target group for such campaigns, as they have a higher tendency to give eWOM in general. Secondly, when developing eWOM messages using self-presentational appeals, the effect may be stronger if these are targeted toward consumers who score high in self-monitoring. These are consumers who should able to self- 
present through both impulsive and reflective eWOM, and thus are less restricted in their approach to eWOM than low self-monitors.

In the remainder of this paper, the author reviews the literature on eWOM, presents the conceptual model of the research, and proposes hypotheses based on theories of eWOM and self-presentation. The hypotheses are tested using survey data from a nationwide representative sample of 574 respondents. Finally, the authors discuss the results and present implications for managers and researchers.

\section{Theoretical background}

\subsection{Literature review and conceptual model}

Electronic word of mouth (eWOM) is defined as "any positive or negative statement made by potential, actual, or former customers about a product or company, which is made available to a multitude of people and institutions via the Internet" (Hennig-Thurau et al., 2004, p. 39). Sharing several similarities with traditional WOM (Eisengerich et al. 2015), eWOM could be partly understood by reviewing the substantial research on WOM that has been developed since the late 1960s (Dichter, 1966). However, eWOM also has some characteristics that makes it different from traditional WOM, such as being (a) written and thus more asynchronous (b) undirected, which involves communicating without a particular person or people in mind, and involving (c) larger audiences (Berger 2013). Consequently, a substantial literature with a special interest in eWOM has emerged (see King et al. 2014, for an excellent meta-analytic review). This literature examines antecedents and consequences of eWOM from both the sender perspective and the receiver perspective.

The current research builds on research that focuses on the antecedents of eWOM from the sender perspective, and is concerned with why consumers give eWOM. Research examining this issue have used several different approaches to categorize the motives of 
WOM production (Berger, 2014; Dichter, 1966; Hennig-Thurau et al., 2004). Inspired by these previous classifications, this study proposes a division of motives into five categories. The first category consists of motives such as individuation (Ho and Dempsey, 2010), selfpresentation (Berger and Iyengar, 2013; Harnish and Bridges, 2016; Pasternak et al., 2017), self-enhancement (Hennig-Thurau et al., 2004), personal reputation (Cheung and Lee, 2012), and self-brand connection (Eelen et al., 2017; Thomas and Saenger, 2017), and is labelled impression management. The second category consists of motives such as social interaction (Hennig-Thurau et al., 2004), sense of belonging (Cheung and Lee, 2012), social bonding (Munzel and Kunz, 2014), and social identity (Arenas-Gaitán et al., 2018; Mousavi et al., 2017), and is labelled social motives. The third category consists of motives such as concern for other consumers (Cheung and Lee, 2012; Hennig-Thurau et al., 2004), altruism (ArenasGaitán et al., 2018; Reimer and Benkenstein, 2016), and helping the company (Eelen et al., 2017; Jeong and Jang, 2011), and is labelled altruistic motives. The fourth category consists of motives such as anxiety reduction (Fu et al., 2015), psychological arousal (Berger and Milkman, 2012), venting (Hennig-Thurau et al., 2004), and revenge (Ward and Ostrom, 2006), and is labelled emotional regulation. The fifth category consists of motives such as expectancy disconfirmation (Banerjee and Chai, 2019; Ho et al., 2017), satisfaction (Darley and Lim, 2018; Jalilvand et al. 2017), and positive emotions (Septianto and Chiew, 2018; Tellis et al., 2019), and is labelled positive emotional experiences.

This study focuses on the impression management category, and aims to extend the knowledge of the link between self-presentation and eWOM production. Specifically, the main aim is to fill a "gap" in the literature regarding the understanding of self-presentation as a predictor of eWOM produced in an impulsive manner. While there is strong evidence of a relationship between self-presentation and reflective eWOM behavior (Berger and Iyengar, 2013), the suggested relationship between self-presentation and impulsive communication 
(Kellermann, 1992; Paulhus, 1993) is yet to be found in an eWOM context. This study approaches this issue by adopting Strack et al.'s (2006) reflective-impulsive model (RIM). This is a dual-system theory that builds on the traditional distinction between two kinds of thinking processes, one fast and intuitive, the other slow and deliberative. Similar dual-system theories, such as the elaboration likelihood model (ELM) and the heuristic-systematic model (HSM), have previously been adopted in examinations on eWOM, with the focus on understanding the process of receiving of eWOM (Gupta and Harris, 2010; Filieri and McLeay, 2014; Park and Kim, 2008). However, the ELM and HSM are less suitable for examining eWOM from the sender perspective as they direct little attention to explaining how the two thinking systems affect human behavior. On the other side, the RIM theory is developed with special attention to explaining human behavior, and suggests that all human behaviors are determined by both reflective and impulsive processes. Hence, it should be highly suitable for explaining the impulsive and reflective determinants of eWOM production. In this study, impulsive and reflective eWOM are considered as behavioral tendencies that are positively related to consumers' overall eWOM production. Self-presentation is also conceptualized as a consumer tendency, and is postulated as a determinant of both reflective and impulsive eWOM tendencies. Further, self-presentation tendency is assumed to affect consumers' overall eWOM production indirectly through the concepts of reflective and impulsive eWOM tendencies. Such indirect effects, if revealed, could provide an understanding of how the reflective and impulsive systems might act as mediators in the selfpresentation-eWOM relationship. At last, self-monitoring is suggested as a moderator in the relationship between the self-presentation tendency and impulsive eWOM tendency. See figure 1 for overview of the conceptual model.

We explore these concepts and their interrelationships in the following sections, beginning with giving an account for the eWOM production concept, followed by presenting 
the RIM theory and its proposed usefulness in understanding the determinants of eWOM production.

Figure 1 here

\section{2 eWOM production}

The focal construct that this research attempts to explain is eWOM production. Some studies examine the production of eWOM as a situational activity that is triggered by a personal experience with a brand/company (Coker and Altobello, 2016) or a product/service (Kim et al., 2016). Others examine eWOM production as an activity that occurs on specific types of platforms such as customer review sites (Jacobsen, 2018), consumer communities (Cheung and Lee, 2012) or social media platforms (Swani et al., 2013). However, eWOM production might also be viewed as a behavioral disposition that occurs across different product categories and across platforms. For instance, research on e-mavens suggests that some consumers regularly transmit market information based on their knowledge across a wide range of product categories and contexts (Darley and Lim, 2018). The current study is interested in testing the premise that eWOM is influenced by human traits such as selfpresentational tendencies and self-monitoring. Thus, eWOM production is conceptualized similarly to e-mavenism (Darley and Lim, 2018) as a general consumer tendency to produce product- and brand related information on the Internet, regardless of category or context.

However, while e-mavens are described as highly knowledgeable consumers that share their expertise, the current study suggests that high knowledge is not a premise for being a highly active eWOM producer. Additionally, eWOM production is not limited to the communication of personal shopping experiences, as is the case of e-mavenism. Rather, it reflects that eWOM, in addition to transmitting personal experiences, also could involve retransmission of what consumers read and hear from others (Angelis et al., 2012). 
Further, the eWOM production concept in this study is concerned with the volume dimension of eWOM (Liu, 2006) and not the valence dimension (Bi et al., 2018). Hence, the focus is on how much eWOM consumers produce regardless of whether they give positive, negative or neutral eWOM. The amount of eWOM that consumers produce has a strong and distinctive influence on consumers' decision-making process (Khare et al., 2011); some suggest an even stronger influence than WOM valence (Liu, 2006). As such, the conceptualization of eWOM production in this study reflects a highly relevant aspect of the eWOM phenomenon, with clear implications for marketing theory and practice.

\subsection{The case for reflective and impulsive eWOM}

The RIM assumes that human behaviors are a function of two distinct systems of information processing: a reflective system and an impulsive system. In the reflective system, behavior is elicited as a consequence of a deliberate and reason-based decision process. This process leads to a decision about the desirability and feasibility of a given action, and requires a high amount of cognitive capacity. In contrast, the impulsive system elicits behavior through a spreading activation process that triggers behavioral schemata, often without any conscious intentions or goals (Strack et al., 2006). This process is more automatic and heuristic-based, involves affective processing of stimuli, and requires little or no cognitive effort.

Although the principles of the reflective and impulsive processes seem contradictory, Strack et al. (2006) suggested that these processes operate in parallel, are concurrently active, and compete for control of an overt response. In other words, a particular behavior is not purely "impulsive" or "reflective." Instead, the RIM assumes that in most situations, both reflective and impulsive components contribute to a particular consumer behavior. Their relative contribution, however, would vary based on contextual factors and personal dispositions. 
Previous applications of the RIM theory focus primarily on buying products and services as the relevant behavior of interest (Lades, 2014; Samson and Voyer, 2012; Strack et al., 2006). The present study suggests a different view on reflective and impulsive processes/systems, relating them to consumers' WOM behavior, and in particular eWOM. Indeed, the literature suggests that eWOM could fit well within the RIM theory.

Firstly, a few recent studies have highlighted the reflective processes underlying WOM production. For instance, Blazevic et al. (2013) suggested that WOM often occurs intentionally based on an activated and conscious goal. When an activated goal triggers WOM, the communication might be considered a strategic tactic to optimize the focal goal attainment. Similarly, Berger and Schwartz (2011) suggested that consumers may give WOM based on a goal-directed and deliberate process. Walther (2007) suggested that such reflective processes are especially prevalent in online communication, as certain characteristics of online channels give consumers more time to construct and plan what to say. Thus, rather than saying whatever comes to mind, people have the opportunity to be more strategic in their communication. Berger and Iyengar (2013) showed that many consumers take advantage of this opportunity when transmitting WOM in online channels, causing a more deliberate and reflective approach to the generation of eWOM.

Secondly, more impulsive processes also seem to underlie the generation of eWOM. For instance, Blazevic et al. (2013) argued that consumers may give WOM without any activated goal in mind, that is, mindlessly and impulsively. Similarly, Mazzarol et al. (2007) found that WOM generation often occurs serendipitously as a result of associations that come up in conversations. This resonates with the findings of Berger and Schwartz (2011), showing that consumers often give WOM based on things cued by the environment. Consumers often seem to give WOM in an unplanned manner based on sudden impulses. Though some research has suggested that such impulsive WOM is most typical for face-to-face 
communication (Berger and Iyengar, 2013), other research has demonstrated that one of the strongest drivers of eWOM is emotions (Phelps, 2004). In particular, emotions that are highly arousing such as awe and anger have been shown to trigger consumers' eWOM behavior (Berger and Milkman, 2012). When emotions are high on arousal, they are likely to weaken the influence of the reflective system and facilitate more automatic responses (Strack and Deutsch, 2004). Similarly, Blazevic et al. (2013) suggested that emotions that cause dissonance or excitement could result in WOM generation that is unintentional and driven by unconscious needs. Hence, impulsive determinants also seem to play an important role in the generation of eWOM.

Based on the above evidence, it seems appropriate to distinguish between eWOM that occurs more impulsively and spontaneously versus eWOM that occurs in a more reflective and planned manner. This study examines these different facets of eWOM production from a consumer trait perspective. This perspective builds on an understanding that people's impulsive and reflective behavioral tendencies are rooted in personality, and thus could be conceptualized as stable individual traits (Hofmann et al., 2008; Verplanken and Herabadi, 2001). Some people are simply more disposed to act on impulses, while others are more disposed to fight off impulses and approach decisions more rationally. These individual differences have previously been studied in relation to consumers' impulse buying tendencies (Rook and Fisher, 1995; Verplanken and Herabadi, 2001), which is empirically established as a stable and universal consumer trait (Steenkamp and Maydeu-Olivares, 2015). It is plausible to assume that consumers also in the context of producing eWOM would possess similar traitlike dispositions.

However, while research on impulsive buying assumes that reflective and impulsive behaviors are at the opposite ends of a single continuum, and that the concept of impulsiveness also captures reflective behavior, the RIM theory suggests that impulsive and 
reflective behaviors are rooted in two distinct systems. Hence, the author introduces the concepts of impulsive eWOM tendency and reflective eWOM tendency. Impulsive eWOM tendency is defined as a consumers' tendency to say things about products and brands in online channels spontaneously, unreflectively, and immediately. Highly impulsive WOM communicators are likely to be relatively unreflective in their approach to WOM, using less time to plan what they will say. Reflective eWOM tendency is defined as consumers' tendency to say things about products and brands in online channels deliberately and reflectively. Highly reflective WOM communicators are likely to be thorough in their approach to WOM, using more time to plan and construct what they will say.

Both the impulsive eWOM tendency and reflective eWOM tendency are expected to have a positive effect on consumers' general tendencies to produce eWOM. Identifying which one of these dispositions is the stronger predictor of eWOM is also of interest to this research. However, in absence of past research that could indicate their relative weights as predictors of eWOM, we offer no formal hypothesis for their relative effects. These are instead explored in the discussions. Consequently, the author proposes the following two hypotheses:

H1: Impulsive eWOM tendency has a positive impact on eWOM production.

H2: Reflective eWOM tendency has a positive impact on eWOM production.

\subsection{Self-presentation as an antecedent of impulsive and reflective eWOM tendencies}

Goffman (1959) suggested that social interactions can be viewed as a performance in which people promote favorable impressions of themselves and avoid unfavorable ones. This tendency to share things to present oneself in a positive light is called self-presentation and is considered a default tendency among people. The degree to which people choose to self- 
present would, however, depend on personal dispositions and the social context people are in (Barasch and Berger, 2014). Online communication is a context in which self-presentation has been shown to be a particularly prominent motive (Walther, 2007). The audience is often larger than in face-to-face communication, and the recipients of one's online communication are more often strangers. Consequently, the online context is likely to be a more pressured condition in terms of making good impressions (Tice et al., 1995). In addition, online communication is predominantly in a written format, which causes a more asynchronous form of communication. This provides consumers more time to construct and refine what to say, which amplifies people's natural tendency to self-present (Walther, 2007). Accordingly, selfpresentation has been identified as one of the strongest motives for producing eWOM (Eisingerich et al., 2015; Hennig-Thurau et al., 2004, Lovett et al., 2014).

Regarding the question of whether self-presentation causes a more reflective or a more impulsive form of eWOM communication, the literature is more ambiguous. In general, there are two research streams that give contradictory answers to the above question. The first theory suggests that self-presentation would most likely initiate a more reflective form of eWOM (Berger and Iyengar, 2013). The underlying explanation is that self-presentation is not something people easily can do spontaneously. Self-presentation involves taking strategic choices about how to appear in the eyes of others, and the assumption is that most consumers need time to optimize these choices. Therefore, consumers driven by self-presentation would rather choose the reflective form of communication allowed by the asynchronous nature of computer-mediated communication, as it would enhance the possibility of portraying the desired image (Walther, 2007). Indeed, Hogan (2010) suggested that most self-presentational behavior in an online context happens through asynchronous rather than through synchronous communication. 
However, another stream of research indicates that self-presentation might also be possible through more impulsive communication. For instance, Kellermann (1992) suggested that all communication, even that which occurs automatically and unintentionally, is inherently strategic and driven by goals such as self-presentation. In other words, being strategic does not contradict being impulsive in one's communication - they are both possible at the same time. Research by Bargh (1989) explains why behaviors that occur automatically might still be goal-driven. He argued that such behaviors would typically be based on welllearned situational scripts or routinized action sequences. The automatized memory structures would guide attention, make behavioral decisions, and direct action within the situation with a minimum of attentional control necessary. In other words, people learn and internalize, through a lifetime practice, how to perform the appropriate behaviors for achieving certain goals. For instance, people learn appropriate communication strategies for achieving selfpresentational goals and are able to perform these strategies with little reflection or memory search. Paulhus (1993) argued that most self-presentation occurs through such unintentional and effortless processes and that automatic self-presentation is the default level of selfpresentation.

In other words, the effect of self-presentation on people's communication tendencies could seemingly work through both reflective and impulsive processes. Thus, the question is, which process dominates when it comes to the production of WOM in an online environment? The general proposition of this study is that self-presentation would primarily give rise to reflective eWOM tendency. This proposition is line with recent research on eWOM by Berger and Iyengar (2013) and is based on the idea that consumers would generally prefer the "safe" option of planning what to say when seeking to achieve self-presentational goals.

However, this study also suggests that consumers may use impulsive eWOM for selfpresentational purposes, depending on their ability to self-present. We adopt the idea that self- 
presentation is not only a motivational factor, but also a skill that influences how effectively people manage their social lives (Vohs et al., 2005). Some people are better equipped to selfpresent and can communicate information about themselves to others in a seemingly effortless fashion and easily get the desired image across, regardless of context. Others, however, find it more difficult to make a desired impression under pressured conditions. Self-monitoring is an individual trait that captures these individual differences and reflects the degree to which a person observes and controls his or her expressive behavior and self-presentation in accord with social cues (Snyder and Gangestad, 1986). High self-monitors are experts at regulating their expressive self-presentation for the sake of desired public appearances (Lennox and Wolfe, 1984). For instance, Harnish and Bridges (2016) showed that among the consumers who post eWOM videos online, those that are high self-monitors are more likely to produce eWOM that fulfils social presentation goals. Having an expertise in performing a particular task would typically involve having developed an automaticity in performing that task (Alba and Hutchinson, 1987). Accordingly, high self-monitors would presumably have developed an automaticity in performing self-presentational behaviors. On the other hand, individuals low in self-monitoring are thought to lack either the ability or the motivation to regulate their expressive self-presentations. Rather, low self-monitors are more likely to act in accordance with their attitudes, traits, or feelings.

Hence, this study suggests that self-monitoring may act as a moderator in the relationship between a self-presentation tendency and an impulsive eWOM tendency. High self-monitors are consumers who can perform self-presentational behaviors with minimal effort and without conscious control. Thus, they should be able to produce eWOM spontaneously while still managing to fulfil their self-presentational needs. On the other hand, those consumers who score low on self-monitoring may be reluctant to use impulsive eWOM, as they may feel a greater need for the extra time to plan what to say. In particular, when they 
are given the opportunity to edit and refine what to say through the asynchrony of online communication, they would expectedly exploit this opportunity and avoid communicating impulsively.

To conclude, this study suggests that self-presentational tendencies may cause impulsive eWOM production among high self-monitors, but not among those with low levels of self-monitoring. Both high and low self-monitors would expectedly be disposed to using reflective eWOM as a means to achieve self-presentational goals, as this constitutes the general mode of online communication. Thus, high self-monitors are expected to have two options when it comes to self-presenting through eWOM: the reflective route, planning carefully what to say; or the impulsive route, saying something "on the fly." For low selfmonitors, the reflective route is presumably the only option. Accordingly, the following hypotheses are posited:

H3: Self-presentation tendency has a positive effect on the impulsive eWOM tendency for high self-monitoring consumers but not for low self-monitoring consumers.

H4: Self-presentation tendency has a positive effect on the reflective eWOM tendency for both high and low self-monitoring consumers.

As mentioned earlier, self-presentation has been identified as a central driver for the production of eWOM (Eisingerich et al., 2015; Hennig-Thurau et al., 2004, Lovett et al., 2014). This research proposes that the effect of self-presentation on eWOM is mediated by the reflective and the impulsive systems. However, in accordance with the above hypotheses, one of these mediation effects is moderated by self-monitoring. Specifically, it is expected that self-presentation would have an indirect effect on eWOM production through impulsive 
eWOM tendency, but only for high self-monitoring consumers. The indirect effect between self-presentation and eWOM production would expectedly appear for both high and low selfmonitors. Hence, this research proposes:

H5: Self-presentation tendency has an indirect effect on eWOM production through the impulsive eWOM tendency for high self-monitoring consumers but not for low selfmonitoring consumers.

H6: Self-presentation tendency has an indirect effect on eWOM production through the reflective eWOM tendency for both high and low self-monitoring consumers.

\section{Methods}

\subsection{Data collection and sample}

To test the hypotheses, the authors conducted an online survey of members from a consumer panel. Respondents were invited to complete the survey by email, which was administered by a professional research company and presented as a survey of general consumer habits. A total of 600 responses were collected from a nationwide representative sample of individuals aged 20-70. Some respondents were removed from the data set due to missing responses or obvious response patterns in their questionnaires. The effective sample size obtained was 574 . Demographically, the sample consisted of $52 \%$ women and $48 \%$ men, and the mean age was 39 years. The panel members were compensated with points that could be used to purchase gifts.

\subsection{Instruments}


All measures were based on the existing literature, but some were adapted for the purposes of the present study. The four items measuring self-presentation tendency were adapted from the public self-consciousness scale from Fenigstein et al. (1975), which has been previously used to assess self-presentation (Ryu og Han, 2009). Self-monitoring was operationalized with five items adopted from the scale developed by Lennox and Wolfe (1984). The measures of impulsive eWOM tendency and reflective eWOM tendency were adapted from scales on impulse buying (Rook and Fisher, 1995; Verplanken and Herabadi, 2001), and each consisted of two items. eWOM production was operationalized with six items, primarily based on Mowen et al. (2007) and Lam (2009). All measurement items were measured with a 7-point Likert-type scale. See Table 1 for an overview of the specific measures.

\section{Table 1 here}

\section{Results}

\subsection{Measurement model analysis}

To test $\mathrm{H} 1$ through H6, we tested a structural equation model specified by the hypothesized relationships, following a two-step model-building approach (Anderson and Gerbing, 1988). First, the measurement instrument was validated using tests for univariate normality and a confirmatory factor analysis (CFA) with the five latent factors measured by 19 items shown in Table 1. In the test of normality, a small cause for concern was the average scores of eWOM tendency that were below the midpoint $($ mean $=2.6$, standard error $=1.5)$ and somewhat positively skewed (skewness $=0.65$ ). However, the skewness value was within the acceptable limits for skewness (Hair et al., 1998), and the measures of the construct were thus considered normal enough to be used in the analysis. The CFA resulted in an acceptable overall fit (GFI= 0.94, $\mathrm{CFI}=0.98, \mathrm{RMSEA}=0.050$ ) according to the usual conventions (Hair et al., 1998; Hu and Bentler, 1999). All indicators load significantly ( $\mathrm{p}<0.001)$ on to their respective 
constructs, thus providing evidence of convergent validity. Composite reliability ranged from 0.88 to 0.98 and AVE ranged from 0.59 to 0.87 , which were above the recommended levels (Fornell and Larker, 1981). The Spearman-Brown statistic recommended to test reliability for constructs measured with two items (Eisinga et al., 2013) showed satisfactory scores for reflective eWOM tendency (0.84) and impulsive eWOM (0.89). Thus, internal consistency reliability of the scale was evidenced. Discriminant validity was assessed by comparing the shared variance (squared correlation) between each pair of constructs against the average of the AVEs for these two constructs (Fornell and Larker, 1981). Within each of the 10 possible pairs of constructs, the shared variance observed is lower than the average of their AVEs, indicating discriminant validity (see Tables 1 and 2).

\section{Table 2 here}

\subsection{Structural model}

A multigroup analysis in Amos was conducted to investigate the hypothesized structural model. Respondents were divided into high and low self-monitoring groups based on a median split. The goodness-of-fit indices for the hypothesized structural model shows acceptable fit (Hair et al., 1998), with $\chi 2(146)=407, \mathrm{GFI}=0.91, \mathrm{CFI}=0.97$, and RMSEA $=$ 0.056. The model accounted for $48 \%$ of the variance in eWOM. Table 3 shows the results of the structural model test, including estimated path coefficients and their corresponding significance levels. Critical ratios computed by AMOS were used to compare these coefficients between the two groups (two-tailed z-test). As a critical ratio above 1.96 implies that the difference between two regression coefficients is significant at 0.05 level, we used the critical ratio to test the moderation hypothesis.

The results show that impulsive eWOM tendency influences eWOM production for both high $(\beta=0.52 ; \mathrm{p}<0.001)$ and low self-monitors $(\beta=0.53 ; \mathrm{p}<0.001)$. These results 
provide support for $\mathrm{H} 1$. The reflective eWOM tendency has also a significant effect on eWOM production for both high $(B=0.41 ; \mathrm{p}<0.001)$ and low self-monitors $(B=0.20 ; \mathrm{p}<$ 0.001), providing support for H2. However, the z-test shows that the effect of reflective eWOM tendency on eWOM production is significantly stronger for high self-monitors than for low self-monitors. This was an unexpected finding, but possible explanations are discussed in the discussion. Further, the results show that self-presentation tendency significantly affects impulsive eWOM tendency for high self-monitors $(B=0.28 ; \mathrm{p}<0.001)$ but not low self-monitors $(\beta=0.07 ; p=0.26)$. The $\mathrm{z}$-test confirms that there is a significant difference in the regression coefficients between these groups. This finding supports the moderation hypothesis the author posits in H3. The relationship between the self-presentation tendency and reflective eWOM tendency is significant for both high $(\beta=0.40 ; p<0.001)$ and low self-monitoring $(\beta=0.29 ; \mathrm{p}<0.001)$, supporting $\mathrm{H} 4$.

\section{Table 3 here}

\subsection{Mediation}

Following the procedures outlined by Preacher and Hayes (2008), bias-corrected bootstrapping (5000 samples taken from the data set) tested the mediating effects of reflective and impulsive eWOM tendencies for both high and low self-monitors. Table 4 shows the results of the bootstrapping tests. In the high self-monitoring group, the indirect effects of the self-presentation tendency on eWOM production via both reflective and impulsive eWOM tendencies are significant, with a $95 \%$ confidence interval (CI) excluding zero $(0.10$ to 0.26 for reflective eWOM, 0.08 to 0.26 for impulsive eWOM). In the low self-monitoring group, the indirect effect of self-presentation tendency on eWOM production via reflective eWOM tendency is significant, with a $95 \%$ confidence interval excluding zero (0.01 to 0.11$)$. The indirect effect of self-presentation tendency on eWOM production via impulsive eWOM 
tendency is not significant, with a $95 \%$ confidence interval including zero (- 0.03 to 0.12 ).

These results are in accordance with the expectations, hence H5 and H6 were supported.

\section{Table 4 here}

\section{Discussion}

The purpose of this study was to increase the understanding of the psychological mechanisms that underlie the relationship between self-presentation and eWOM production. Previous research has suggested that self-presentation would motivate the production of eWOM through a reflective thinking process (Berger and Iyengar, 2013). However, consumers often

talk based on their impulses, and some researchers have argued that impulsive communication may also be driven by self-presentation (Kellermann, 1992; Paulhus, 1993). This study tests whether the latter idea is transferrable to the eWOM context by examining self-presentation tendency as an antecedent of consumers' reflective and impulsive eWOM tendencies. The results show that self-presentation tendencies are indeed associated with an impulsive eWOM tendency. However, self-presentation tendencies are only associated with impulsive eWOM for consumers with high levels of self-monitoring, suggesting that self-presenting impulsively demands high self-presentational abilities.

Moreover, the findings show that both impulsive and reflective eWOM processes are associated with an enhanced tendency to produce eWOM. In both the high and low selfmonitoring group, impulsive and reflective eWOM tendencies have significant effects on eWOM production. However, the effect sizes indicate that impulsive eWOM tendency is the strongest predictor, suggesting that the impulsive system is the dominating contributor to eWOM production. 
Finally, this study shows that self-presentation has an indirect effect on eWOM production through both reflective and impulsive eWOM tendencies. The only insignificant path was the one through the impulsive eWOM tendency in the low self-monitoring group.

\subsection{Theoretical implications}

This research makes several contributions to the literature. First, it challenges the idea that self-presentation only translates into a reflective eWOM process and provides an explanatory mechanism for why this might occur. While some previous research suggests that people could self-present using the impulsive system (Kellermann, 1992; Paulhus, 1993), no research has, until now, found this effect in an online context. By including self-monitoring as a moderator, this study shows that self-presentational abilities is a key factor for why impulsive communication also could occur in an online context. Those who have such abilities should presumably be able to self-present automatically, that is, with minimal effort and without conscious control (Alba and Hutchinson, 1989). Thus, impulsive online communication could be as much of a "safe" option as reflective online communication when these consumers want to self-present. Yet, given the significant effect that self-presentation has on the reflective eWOM tendency for both high and low self-monitors, the reflective mode of communication still seems like the dominant option when consumers want to self-present. Thus, this study confirms the results of previous works (Berger and Iyengar, 2013; Walther, 2007), but at the same time, it shows that the effect of self-presentation on consumers' online communication mode may be more nuanced than these previous studies suggest.

Second, while previous research shows that eWOM might be a function of factors that are related to both reflective and impulsive processes (Berger and Schwartz, 2011; Blazevic et $a l ., 2013)$, this research is the first to synthesize these factors into two distinctive concepts. Indeed, the results show that the tendency to say things about products and brands in online 
channels reflectively is clearly a separate consumer disposition from having the tendency to say things about products and brands in online channels impulsively. This resonates with the RIM theory (Strack et al., 2006), which suggests that all consumer behaviors are a function of both impulsive and reflective processes. Further, the RIM theory suggests that which mental system dominates in driving a particular behavior depends on contextual factors and consumers' personal dispositions. The results of the current study resonate well with these principles of the RIM theory, showing that self-monitoring plays a moderating role in determining which mental system dominates in driving eWOM. In other words, the theory provides a usable framework for understanding the mental determinants of eWOM production and how these determinants differ in their effects on eWOM based on personal factors.

Third, as this is the first study to synthesize the reflective and impulsive mental processes into two distinct determinants of eWOM, this is also the first study to examine the relative contribution of these concepts in the generation of eWOM. By comparing the effect sizes of these concepts on eWOM production, the impulsive eWOM tendency seems to be the strongest determinant in both the high and low self-monitoring groups. While the impulsive system was expected to influence eWOM production, previous research has indicated that impulsive communication is most common in face-to-face settings (Berger and Schwartz, 2011) and that online communication is mostly driven by reflective eWOM (Berger and Iyengar, 2013). Hence, this research shows that impulsiveness as a predictor of eWOM might be more important than previously assumed. A potential explanation for this effect could be that consumers who are driven by an impulsive eWOM tendency are not restricted by the need to plan what to say and could talk on the "fly" about whatever comes to their mind. Thus, they should be able to talk and share things online more frequently, and their eWOM production could be similar to the ongoing WOM communication that is common in offline conversations (Berger and Schwartz, 2011). Impulsive eWOM producers who are low self- 
monitors might be even freer when giving eWOM, as they are not driven by self-presentation. Instead, they might talk about whatever is cued by the environment or that has evoked a strong emotional reaction in them, without using too much energy on saying something interesting.

Another possible explanation for why the impulsive eWOM tendency seems to be the strongest determinant of eWOM production could be that producing eWOM through a reflective system could drain self-regulatory resources (Vohs et al., 2005), which could prevent people with a reflective eWOM tendency from giving eWOM frequently. This theory is supported by the significantly higher importance of the reflective eWOM tendency as a predictor of eWOM production in the high versus the low self-monitoring group. Consumers with a lower ability to self-present should be drained faster in terms of self-regulatory resources when planning what to say online. On the other hand, being a high self-monitor individual could make reflective eWOM production a less effortful process and would presumably make him or her capable of a high eWOM production using either mental system.

\subsection{Practical implications}

To take advantage of the power of eWOM, marketers are employing various strategies such as engaging customers through social media (Swani et al., 2013), developing “social buzz" campaigns (Coker and Altobello, 2016), or executing seeding campaigns among bloggers (Kozinets et al., 2010). The success of any of these strategies hinges on triggering consumers' motivation to talk, which necessitates an understanding of the motivational factors underlying the eWOM generation. Previous research has suggested that self-presentation is an important motive for producing eWOM, but that its effect is limited to a reflective form of eWOM (Berger and Iyengar, 2013) which could make it less effective for stimulating ongoing eWOM communication (Berger and Schwartz, 2011). The current research suggests that self- 
presentation could also give rise to impulsive eWOM and thus should be able to stimulate a more ongoing type of communication. Consequently, self-presentation might be an even more important driver of eWOM than previously assumed.

Marketers should exploit this insight by adopting self-presentation as a focal element in their eWOM strategies. For instance, when aiming to achieve viral effects in social media, companies should focus on designing content that is entertaining, useful or relevant to people's self-concept, as these are elements that could trigger consumers' need for selfpresentation (Berger, 2014). Such content would be particularly effective if it is targeted at consumers with high self-monitoring as these should be able to self-present through impulsive eWOM. As shown in this research, impulsive eWOM is associated with a general stronger tendency to produce eWOM. Thus, by combining the creation of self-presentational content with targeting of high self-monitors, companies may be able to stimulate higher volumes of eWOM than they would without such targeting. For instance, companies may try to identify online influencers that appear to have strong abilities in adapting their self-presentational behaviors, and provide them with original or surprising information about the companies' products, or with useful product videos or blog posts that make the influencer seem smart or helpful.

\subsection{Limitations and future research}

This research is subject to several limitations that should be addressed in future research. One primary weakness was the use of two-item scales in measuring impulsive and reflective eWOM tendencies. Although these items were adapted from well-established measures on impulse buying (Rook and Fisher, 1995), the author recognizes that using only two items diminishes construct validity by decreasing the likelihood of adequately covering the domain 
of the constructs. Further research is therefore required to develop more robust multiple-item scales for the constructs, and validating them across different contexts and cultures.

Another weakness of this study was the use of self-reported measures rather than observational behaviors. As such, there is the potential for inaccuracy due to people's introspective abilities or social desirability tendencies. For instance, Reynolds et al. (2006) showed that self-reported measures of impulsivity generate different results than behavioral measures of impulsivity. Future research might therefore use experimental designs to test the relationships examined herein.

The current study shows that self-presentation is an important driver of eWOM, but not for consumers who score low on self-monitoring and has an impulsive eWOM tendency. What drives these consumers' eWOM production should be the object of future investigation. For instance, are these consumers driven mostly by unconscious factors such as emotions (Berger and Milkman, 2012) and accessibility (Berger and Schwartz, 2011), or could they also be driven by more intentional motives such as helping others or persuasion (Berger, 2014)?

Future research should also consider moderating factors in the relationship between the reflective and impulsive systems and eWOM production. While this study shows that the impulsive eWOM tendency is relatively more important than the reflective eWOM tendency, there might be situations where the opposite occurs. For instance, would consumers with strong product involvement be more driven by a reflective versus an impulsive eWOM tendency (Blazevic et al., 2013)? Furthermore, could there be any factors that would make the effect of impulsive eWOM communication even more dominant than in this study. Lurie et al. (2014) showed that eWOM via mobile devices tends to be written in real time, whereas desktop eWOM is written after a longer time delay. Does this indicate that the impulsive 
eWOM tendency is an even stronger predictor of eWOM when mobile is the communication device?

The current study focuses on the volume aspect of eWOM. Future research could extend to investigating how the impulsive and the reflective eWOM tendencies are related to other aspects of eWOM such as valence. For instance, since impulsivity is typically rooted in a personality characterized by higher levels of emotional instability (Steenkamp and MaydeuOlivares, 2015), it could be expected that impulsive eWOM would have a stronger relationship with negative than with positive eWOM. On the other hand, reflective individuals would typically be more strategic in their communication, and presumably transmit more positive eWOM as this put them in a better light (Berger, 2014).

A final avenue for future research is to examine how consumers with either a reflective or an impulsive eWOM tendency affects the receiver of eWOM. One possibility is that reflective eWOM producers have a relatively weaker influence on the receiver, as consumers dislike people who engage in deliberate self-presentation (Blazevic et al., 2013). Another possibility is that reflective eWOM producers are more influential, as these use more time to construct what to say, and thus might be perceived as more credible.

\section{References}

Alba, J.W., and Hutchinson, J.W. (1987). "Dimensions of consumer expertise", Journal of Consumer Research, Vol. 13 No. 4, pp. 411-454.

Anderson, J.C. and Gerbing, D.W. (1988). "Structural equation modeling in practice: A review and recommended two-step approach", Psychological Bulletin, Vol. 103 No. 3, pp. 411. 
Angelis, M.D., Bonezzi, A., Peluso, A.M., Rucker, D.D. and Costabile, M. (2012). "On braggarts and gossips: A self-enhancement account of word-of-mouth generation and transmission", Journal of Marketing Research, Vol. 49 No. 4, pp. 551-563.

Arenas-Gaitán, J., Rondan-Cataluna, F.J. and Ramirez-Correa, P.E. (2018). "Antecedents of WOM: SNS-user segmentation", Journal of Research in Interactive Marketing, Vol. 12 No. 1, pp. 105-124.

Banerjee, S. and Chai, L. (2019). "Effect of Individualism on Online User Ratings: Theory and Evidence", Journal of Global Marketing, (prepublished online January 25). DOI: $10.1080 / 08911762.2018 .1549690$

Barasch, A. and Berger, J. (2014). "Broadcasting and narrowcasting: How audience size affects what people share", Journal of Marketing Research, Vol. 51 No. 3, pp. 286299.

Bargh, J.A. (1989). "Conditional automaticity: Varieties of automatic influence in social perception and cognition", Unintended Thought, Vol. 3, pp. 51-69.

Berger, J. (2013). "Beyond viral: Interpersonal communication in the internet age", Psychological Inquiry, Vol. 24 No. 4, pp. 293-296.

Berger, J. (2014). "Word of mouth and interpersonal communication: A review and directions for future research", Journal of Consumer Psychology, Vol. 24 No. 4, pp. 586-607.

Berger, J. and Iyengar, R. (2013). "Communication channels and word of mouth: How the medium shapes the message", Journal of Consumer Research, Vol. 40 No. 3, pp. 567579.

Berger, J. and Milkman, K.L. (2012). "What makes online content viral?", Journal of Marketing Research, Vol. 49 No. 2, pp. 192-205.

Berger, J. and Schwartz, E.M. (2011). "What drives immediate and ongoing word of mouth?", Journal of Marketing Research, Vol. 48 No. 5, pp. 869-880. 
Bi, N.C., Zhang, R. and Ha, L. (2019). "Does valence of product review matter? The mediating role of self-effect and third-person effect in sharing YouTube word-ofmouth (vWOM)", Journal of Research in Interactive Marketing, Vol. 13 No. 1, pp. $79-95$.

Blazevic, V., Hammedi, W., Garnefeld, I., Rust, R.T., Keiningham, T., Andreassen, T.W., ... and Carl, W. (2013). "Beyond traditional word-of-mouth: An expanded model of customer-driven influence", Journal of Service Management, Vol. 24 No. 3, pp. 294313.

Cheung, C.M. and Lee, M.K. (2012). "What drives consumers to spread electronic word of mouth in online consumer-opinion platforms", Decision support systems, Vol. 53 No. 1, pp. 218-225.

Coker, K.K. and Altobello, S.A. (2016). "The role of disclosure of social shopping rewards in social buzz", Journal of Research in Interactive Marketing, Vol. 10 No. 4, pp. 321337.

Dichter, E. (1966). "How word of mouth advertising works", Harvard Business Review, Vol. 44 No. November-December, pp. 147-166

Darley, W. and Lim, J.S. (2018). "Mavenism and e-maven propensity: antecedents, mediators and transferability", Journal of Research in Interactive Marketing, Vol. 12 No. 3, pp. 293-308.

Dunne, Á., Lawlor, M.A. and Rowley, J. (2010). "Young people's use of online social networking sites-a uses and gratifications perspective", Journal of Research in Interactive Marketing, Vol. 4 No. 1, pp. 46-58.

Eelen, J., Özturan, P. and Verlegh, P.W. (2017). "The differential impact of brand loyalty on traditional and online word of mouth: The moderating roles of self-brand connection 
and the desire to help the brand", International Journal of Research in Marketing, Vol. 34 No. 4, pp. 872-891.

Eisinga, R. Te Grotenhuis, M. and Pelzer, B. (2013). "The reliability of a two-item scale: Pearson, Cronbach, or Spearman-Brown?", International Journal of Public Health, Vol. 58 No. 4, pp. 637-642.

Eisingerich, A.B., Chun, H.H., Liu, Y., Jia, H.M. and Bell, S.J. (2015). "Why recommend a brand face-to-face but not on Facebook? How word-of-mouth on online social sites differs from traditional word-of-mouth", Journal of Consumer Psychology, Vol. 25 No. 1, pp. 120-128

Fenigstein, A., Scheier, M.F. and Buss, A.H. (1975). "Public and private self-consciousness: Assessment and theory", Journal of Consulting and Clinical Psychology, Vol. 43 No. 4, pp. 522.

Filieri, R. and McLeay, F. (2014). "E-WOM and accommodation: An analysis of the factors that influence travelers' adoption of information from online reviews", Journal of Travel Research, Vol. 53 No. 1, pp. 44-57.

Fornell, C. and Larcker, D.F. (1981). "Evaluating structural equation models with unobservable variables and measurement error", Journal of Marketing Research, Vol. 18 No. 1, pp. 39-50.

Fu, J.R., Ju, P.H., \& Hsu, C.W. (2015). "Understanding why consumers engage in electronic word-of-mouth communication: Perspectives from theory of planned behavior and justice theory", Electronic Commerce Research and Applications, Vo. 14 No. 6, pp. 616-630.

Goffman, E. (1959). The presentation of self in everyday life. New York: Anchor Books. 
Gupta, P. and Harris, J. (2010). "How e-WOM recommendations influence product consideration and quality of choice: A motivation to process information perspective", Journal of Business Research, Vol. 63 No. 9-10, pp. 1041-1049.

Hair, J.F., Black, W.C., Babin, B.J., Anderson, R.E. and Tatham, R.L. (1998). Multivariate Data Analysis (Vol. 5, No. 3, pp. 207-219). Upper Saddle River, NJ: Prentice hall.

Harnish, R.J. and Bridges, K.R. (2016). "Mall Haul Videos: Self-Presentational Motives and the Role of Self-Monitoring", Psychology \& Marketing, Vol. 33 No. 2, pp. 113-124.

Hennig-Thurau, T., Gwinner, K.P., Walsh, G. and Gremler, D.D. (2004). "Electronic word-ofmouth via consumer-opinion platforms: What motivates consumers to articulate themselves on the internet?", Journal of Interactive Marketing, Vol. 18 No. 1, pp. 3852.

Ho, J.Y. and Dempsey, M. (2010). "Viral marketing: Motivations to forward online content", Journal of Business Research, Vol. 63 No. 9-10, pp. 1000-1006.

Ho, Y.C., Wu, J. and Tan, Y. (2017). "Disconfirmation effect on online rating behavior: A structural model", Information Systems Research, Vol. 28 No. 3, pp. 626-642.

Hofmann, W., Gschwendner, T., Friese, M., Wiers, R.W. and Schmitt, M. (2008). "Working memory capacity and self-regulatory behavior: Toward an individual differences perspective on behavior determination by automatic versus controlled processes", Journal of Personality and Social Psychology, Vol. 95 No. 4, pp. 962.

Hogan, B. (2010). "The presentation of self in the age of social media: Distinguishing performances and exhibitions online", Bulletin of Science, Technology \& Society, Vol. 30 No. 6, pp. 377-386.

Hu, L.T. and Bentler, P.M. (1999). "Cutoff criteria for fit indexes in covariance structure analysis: Conventional criteria versus new alternatives", Structural Equation Modeling: A Multidisciplinary Journal, Vol. 6 No. 1, pp. 1-55. 
Huang, M., Cai, F., Tsang, A.S. and Zhou, N. (2011). "Making your online voice loud: The critical role of WOM information", European Journal of Marketing, Vol. 45 No. 7/8, pp. 1277-1297.

Jacobsen, S. (2018). "Why did I buy this? The effect of WOM and online reviews on post purchase attribution for product outcomes", Journal of Research in Interactive Marketing, Vol. 12 No. 3, pp. 370-395.

Jalilvand, M.R., Salimipour, S., Elyasi, M. and Mohammadi, M. (2017). "Factors influencing word of mouth behaviour in the restaurant industry", Marketing Intelligence \& Planning, Vol. 35 No. 1, pp. 81-110.

Jeong, E., and Jang, S.S. (2011). "Restaurant experiences triggering positive electronic wordof-mouth (eWOM) motivations", International Journal of Hospitality Management, Vol. 30 No. 2, pp. 356-366.

Keller, E. and Fay, B. (2012). "Word-of-mouth advocacy", Journal of Advertising Research, Vol. 52 No. 4, pp. 459-464.

Kellermann, K. (1992). "Communication: Inherently strategic and primarily automatic", Communications Monographs, Vol. 59 No. 3, pp. 288-300.

Khare, A., Labrecque, L.I. and Asare, A.K. (2011). "The assimilative and contrastive effects of word-of-mouth volume: an experimental examination of online consumer ratings", Journal of Retailing, Vol. 87 No. 1, pp. 111-126.

Kim, H. (2014). "The role of WOM and dynamic capability in B2B transactions", Journal of Research in Interactive Marketing, Vol. 8 No. 2, pp. 84-101.

King, R.A., Racherla, P. and Bush, V.D. (2014). "What we know and don't know about online word-of-mouth: A review and synthesis of the literature", Journal of Interactive Marketing, Vol. 28 No. 3, pp. 167-183. 
Kozinets, R.V., De Valck, K., Wojnicki, A.C. and Wilner, S.J. (2010). "Networked narratives: Understanding word-of-mouth marketing in online communities", Journal of Marketing, Vol. 74 No. 2, pp. 71-89.

Lades, L.K. (2014). "Impulsive consumption and reflexive thought: Nudging ethical consumer behavior", Journal of Economic Psychology, Vol. 41, pp. 114-128.

Lam, D., Lee, A. and Mizerski, R. (2009). "The effects of cultural values in word-of-mouth communication", Journal of International Marketing, Vol. 17 No. 3, pp. 55-70.

Lennox, R.D. and Wolfe, R.N. (1984). "Revision of the self-monitoring scale", Journal of Personality and Social Psychology, Vol. 46 No. 6, pp. 1349-1364.

Liu, Y. (2006). "Word of mouth for movies: its dynamics and impact on box office revenue", Journal of Marketing, Vol. 70 No. 3, pp. 74-89.

Lovett, M.J., Peres, R. and Shachar, R. (2013). "On brands and word of mouth", Journal of Marketing Research, Vol. 50 No. 4, pp. 427-444.

Lurie, N.H., Ransbotham, S. \& Liu H. (2014). "The Characteristics and Perceived Value of Mobile Word of Mouth", Marketing Science Institute Report, pp. 14-109.

Mazzarol, T., Sweeney, J.C. and Soutar, G.N. (2007). "Conceptualizing word-of-mouth activity, triggers and conditions: An exploratory study", European Journal of Marketing, Vol. 41 No. 11/12, pp. 1475-1494.

Mowen, J.C., Park, S. and Zablah, A. (2007). "Toward a theory of motivation and personality with application to word-of-mouth communications", Journal of Business Research, Vol. 60 No. 6, pp. 590-596.

Mousavi, S., Roper, S. and Keeling, K.A. (2017). "Interpreting social identity in online brand communities: Considering posters and lurkers", Psychology \& Marketing, Vol. 34 No. 4, pp. 376-393. 
Munzel, A. and Kunz, W.H. (2014). "Creators, multipliers, and lurkers: who contributes and who benefits at online review sites", Journal of Service Management, Vol. 25 No. 1, pp. 49-74.

Park, D.H. and Kim, S. (2008). "The effects of consumer knowledge on message processing of electronic word-of-mouth via online consumer reviews", Electronic Commerce Research and Applications, Vol. 7 No. 4, pp. 399-410.

Pasternak, O., Veloutsou, C. and Morgan-Thomas, A. (2017). "Self-presentation, privacy and electronic word-of-mouth in social media", Journal of Product \& Brand Management, Vol. 26 No. 4, pp. 415-428.

Paulhus, D.L. (1993). Bypassing the will: The automatization of affirmations. In D. M. Wegner \& J. W. Pennebaker (Eds.), Handbook of Mental Control (pp. 573-587). Englewood Cliffs, NJ: Prentice Hall.

Phelps, J. E., Lewis, R., Mobilio, L., Perry, D. and Raman, N. (2004). "Viral marketing or electronic word-of-mouth advertising: Examining consumer responses and motivations to pass along email", Journal of Advertising Research, Vol. 44 No. 4, pp. 333-348.

Preacher, K.J. and Hayes, A.F. (2008). "Asymptotic and resampling strategies for assessing and comparing indirect effects in multiple mediator models", Behavior Research Methods, Vol. 40 No. 3, pp. 879-891.

Reimer, T. and Benkenstein, M. (2016). "Altruistic eWOM marketing: More than an alternative to monetary incentives", Journal of Retailing and Consumer Services, Vol. 31, pp. 323-333.

Reynolds, B., Ortengren, A., Richards, J. B. and de Wit, H. (2006). "Dimensions of impulsive behavior: Personality and behavioral measures", Personality and Individual Differences, Vol. 40 No. 2, pp. 305-315. 
Rook, D.W. and Fisher, R.J. (1995). "Normative influences on impulsive buying behavior ", Journal of Consumer Research, Vol. 22 No. 3, pp. 305-313.

Ryu, G. and Han, J.K. (2009). "Word-of-mouth transmission in settings with multiple opinions: The impact of other opinions on WOM likelihood and valence", Journal of Consumer Psychology, Vol. 19 No. 3, pp. 403-415.

Samson, A. and Voyer, B.G. (2012). "Two minds, three ways: dual system and dual process models in consumer psychology. AMS Review, Vol. 2 No. 2-4, 48-71.

Schivinski, B. and Dabrowski, D. (2015). "The impact of brand communication on brand equity through Facebook", Journal of Research in Interactive Marketing, Vol. 9 No. 1, pp. 31-53.

Septianto, F. and Chiew, T. M. (2018). "The effects of different, discrete positive emotions on electronic word-of-mouth", Journal of Retailing and Consumer Services, Vol. 44, pp. $1-10$.

Snyder, M. (1974). "Self-monitoring of expressive behavior", Journal of Personality and Social Psychology, Vol. 30 No. 4, pp. 526.

Snyder, M. and Gangestad, S. (1986). "On the nature of self-monitoring: Matters of assessment, matters of validity", Journal of Personality and Social Psychology, Vol. 51 No. 1, pp. 125.

Strack, F. and Deutsch, R. (2004). "Reflective and impulsive determinants of social behavior", Personality and Social psychology Review, Vol. 8 No. 3, pp. 220-247.

Strack, F. and Deutsch, R. (2006). "Reflective and impulsive determinants of consumer behavior", Journal of Consumer Psychology, Vol. 16 No. 3, pp. 205-216.

Steenkamp, J.B.E. and Maydeu-Olivares, A. (2015). "Stability and change in consumer traits: evidence from a 12-year longitudinal study, 2002-2013", Journal of Marketing Research. Vol. 52 No. 3, pp. 287-308. 
Swani, K., Milne, G. and P. Brown, B. (2013). "Spreading the word through likes on Facebook: Evaluating the message strategy effectiveness of Fortune 500 companies", Journal of Research in Interactive Marketing, Vol. 7 No. 4, pp. 269-294.

Tellis, G. J., MacInnis, D. J., Tirunillai, S. and Zhang, Y. (2019). "What drives virality (Sharing) of online digital content? The critical role of information, emotion, and brand prominence", Journal of Marketing, Vol. 83 No. 4, pp. 1-20.

Thomas, V.L. and Saenger, C. (2017). "Promoting or protecting my brand: the identityexpression and fear-of-imitation conflict", Journal of Consumer Marketing, Vol. 34 No. 1, pp. 66-73.

Tice, D.M., Butler, J.L., Muraven, M.B. and Stillwell, A.M. (1995). "When modesty prevails: Differential favorability of self-presentation to friends and strangers", Journal of Personality and Social Psychology, Vol. 69 No. 6, pp. 1120.

Verplanken, B. and Herabadi, A. (2001). "Individual differences in impulse buying tendency: Feeling and no thinking", European Journal of Personality, Vol. 15 No. 1.

Vohs, K.D., Baumeister, R.F. and Ciarocco, N.J. (2005). "Self-regulation and selfpresentation: regulatory resource depletion impairs impression management and effortful self-presentation depletes regulatory resources", Journal of Personality and Social Psychology, Vol. 88 No. 4, pp. 632.

Walther, J.B. (2007). "Selective self-presentation in computer-mediated communication: Hyperpersonal dimensions of technology, language, and cognition", Computers in Human Behavior, Vol. 23 No. 5, pp. 2538-2557.

Ward, J.C. and Ostrom, A.L. (2006). "Complaining to the masses: The role of protest framing in customer-created complaint web sites", Journal of Consumer Research, Vol. 33 No. 2, pp. $220-230$. 
Table 1: Confirmatory factor analysis and measurement properties of the scales

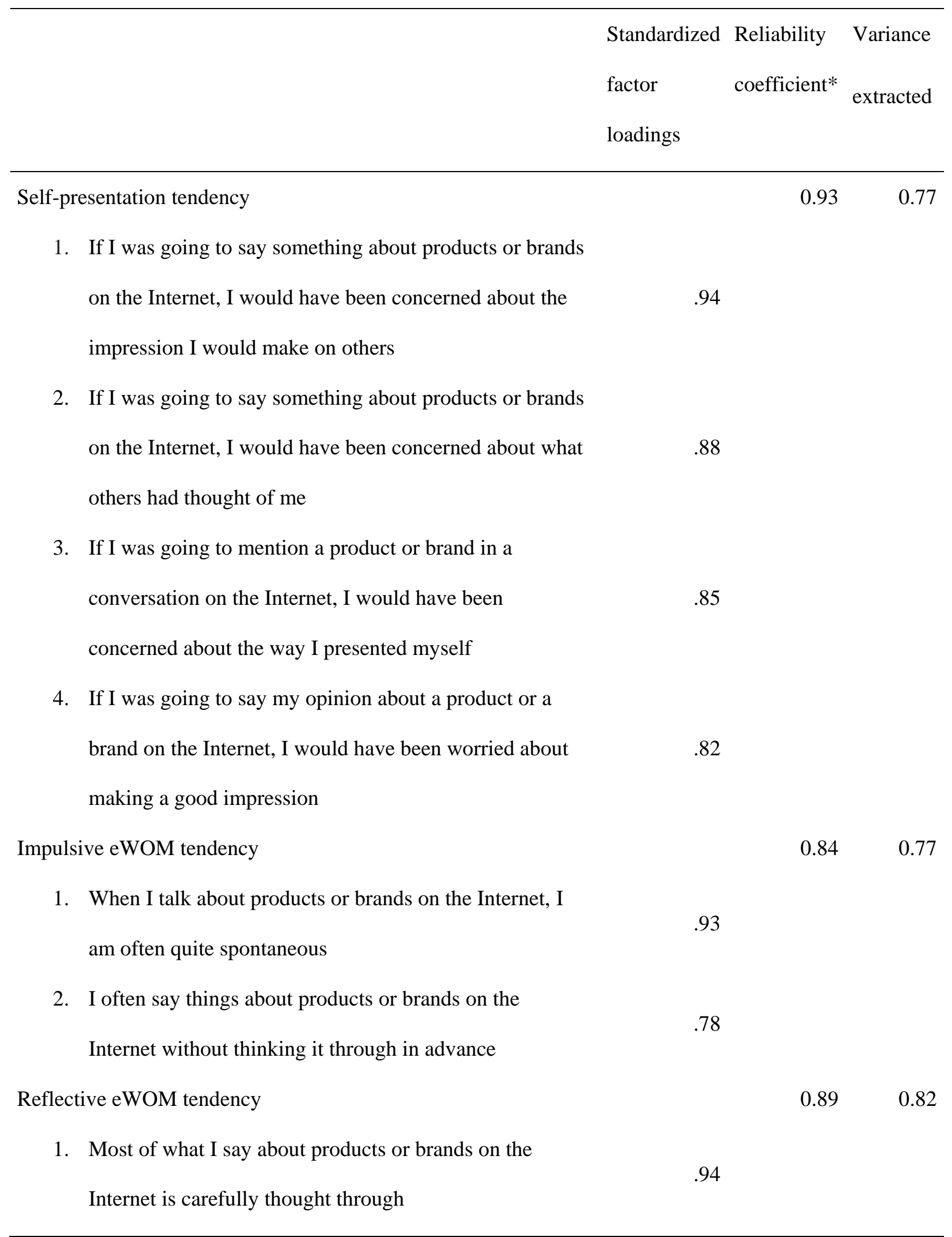


2. I carefully plan what to say when talking about products

or brands on the Internet

eWOM production

1. I like introducing new brands and products to my friends and family through the Internet

2. I like to talk to others about my product and brand experiences on the Internet

3. I share information about new brands and products on the Internet with people other than my close friends and family

4. I often tell others about new products and brands through the Internet

5. I usually spend a lot of time on the Internet sharing my knowledge about products and brands

6. I share brand and product information actively with others through the Internet

1. In social situations, I have the ability to alter my behavior if I feel that something else is called for.

2. I have the ability to control the way I come across to people, depending on the impression I wish to give them

3. When I feel that the image I am portraying isn't working, I can readily change it to something that does

4. I have found that I can adjust my behavior to meet the requirements of any situation I find myself in

5. Once I know what the situation calls for, it's easy for me to regulate my actions accordingly 
Table 2: Correlations, means, and standard deviations

\begin{tabular}{lccccc}
\hline & $\mathbf{1}$ & $\mathbf{2}$ & $\mathbf{3}$ & $\mathbf{4}$ & $\mathbf{5}$ \\
\hline 1. Self-presentation & - & & & \\
2. Impulsive eWOM & $0.17^{* *}$ & - & & \\
3. Reflective eWOM & $0.35^{* *}$ & $0.38^{* *}$ & - & & \\
4. eWOM production & $0.24^{* *}$ & $0.60^{* *}$ & $0.48^{* *}$ & - & - \\
5. Self-monitoring & $0.17^{* *}$ & $0.15^{* *}$ & $0.22^{* *}$ & $0.28^{* *}$ & \\
& & & & & \\
M & 3.7 & 3.1 & 3.6 & 2.6 & 1.1 \\
SD & 1.6 & 1.5 & 1.6 & 1.5 & \\
\hline$* p<0.05: * * p<0.01$ & & & &
\end{tabular}

Table 3: Test of structural model and research hypotheses

High self-monitors Low self-monitors

\begin{tabular}{lccc}
\hline Hypothesized effects & $\beta$ & $\beta$ & Z-score \\
\hline Impulsive eWOM tendency -> eWOM & $0.52^{* *}$ & $0.53^{* *}$ & -0.49 \\
production & & & $-3.73^{* *}$ \\
Reflective eWOM tendency -> eWOM & $0.41^{* *}$ & $0.20^{* *}$ & \\
production & & & $-2.36^{* *}$ \\
Self-presentation -> Impulsive eWOM & $0.28^{* *}$ & 0.07 & -0.89 \\
tendency & & & \\
Self-presentation $->$ Reflective eWOM & $0.40^{* *}$ & $0.29 * *$ & \\
tendency & & & \\
\hline$p p<0.05: * * p<0.01$ & & &
\end{tabular}


Table 4: Bootstrap test of indirect effects

High self-monitors $\quad$ Low self-monitors

$\beta \quad 95 \% \mathrm{CI} \quad \beta \quad 95 \% \mathrm{CI}$

LL UL LL UP

\begin{tabular}{|c|c|c|c|c|c|c|}
\hline $\begin{array}{l}\text { Self-presentation -> Reflective eWOM -> } \\
\text { eWOM production }\end{array}$ & 0.17 & 0.10 & 0.26 & 0.06 & 0.01 & 0.11 \\
\hline $\begin{array}{l}\text { Self-presentation -> Impulsive eWOM -> } \\
\text { eWOM production }\end{array}$ & 0.16 & 0.08 & 0.26 & 0.04 & -0.03 & 0.12 \\
\hline
\end{tabular}

Figure 1: Conceptual model

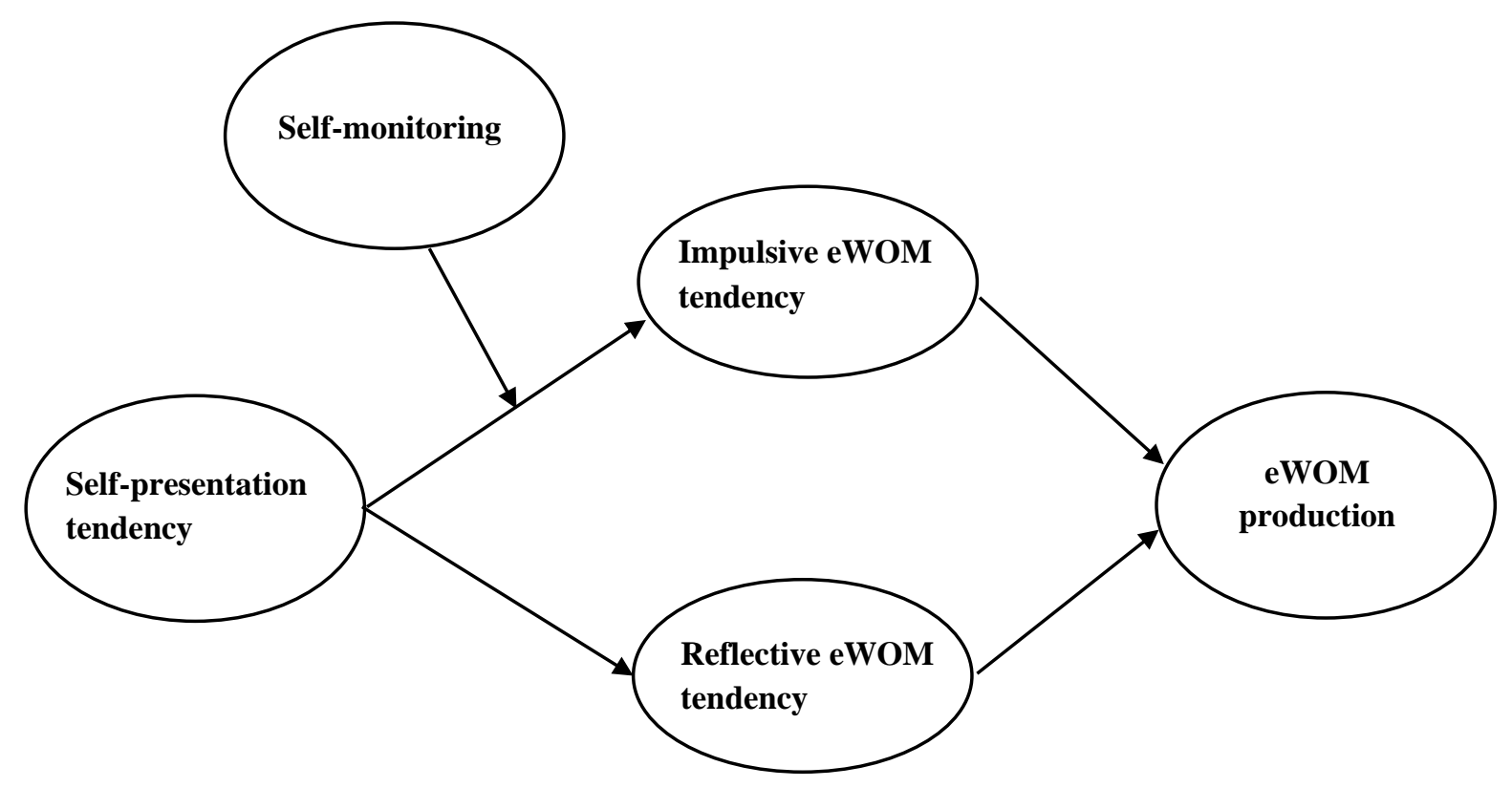

